\title{
Geometric Error Measurement and Identification for Rotational Axes of a Five-Axis CNC Machine Tool
}

\author{
Yanbing $\mathrm{Ni}^{1},{ }^{*}-$ Xiance Liu ${ }^{1}-$ Biao Zhang 2 - Zhiwen Zhang 1 - Jinhe $\mathrm{Li}^{1}$ \\ 1 Tianjin University, School of Mechanical Engineering, China \\ 2 Qingdao Hisense - Hitachi Air Conditioning System Co. Ltd, China
}

\begin{abstract}
It is difficult to measure the attitude errors of five-axis machine tools, as it requires expensive instruments. Furthermore, it is hard to measure and identify them at production sites. In this paper, the B/C type of five-axis CNC machine tool is studied; the rotational axes are in the cutting tool movement chain and workpiece movement chain. The method of geometric error measurement and identification of the rotational axes is proposed based on the use of a double ball bar (DBB). The geometric error sources in two rotational axes are analysed. Then, based on the homogeneous coordinate transformation principle, the relationships between the geometric errors of each rotational axis and the structure parameters of the machine tool are established on the $C$ turntable and $B$ swinging head, respectively. Identification models for each axis are built by changing the installation modes of the DBB in three coordinate directions. The geometric errors in the rotational axes are identified by the least-squares method. Finally, the error measurement experiment of the machine tool is carried out for different installation modes of a DBB. The experimental results show that the identified error parameters are consistent with actual conditions and verify the validity and feasibility of the proposed method.
\end{abstract}

Keywords: five-axis CNC machine tool; double ball bar; error modelling; error measurement and identification

\section{Highlights}

- A geometric error measurement and identification method is proposed for the rotational axes of a B/C type of five-axis CNC machine tool based on DBB.

- The rotation axes are in the cutting tool and workpiece movement chains.

- $\quad$ Different DBB installation methods are designed in three directions. Seven measurements were accomplished in three measurement modes and an identification model for each axis established.

- Experiments are carried out by DBB in different measuring modes, and the least-squares solution of the system of overdetermined equations is obtained. Six geometric errors of each rotation axis are identified.

\section{INTRODUCTION}

Five-axis CNC machine tools are widely used in manufacturing. It is difficult to guarantee accuracy since rotational axes are involved in multi-axis control. The basic geometric accuracy of machine tools is the foundation of their comprehensive accuracy. Therefore, geometric errors must be controlled. Based on the established error models, error measurement and identification are the keys to realising error compensation [1] to [3]. According to the differences in measuring instruments and methods, error measurement is divided into single error measurement and comprehensive error measurement. Single error measurement is direct, but its measurement period is long, and the environmental requirements are strict: in some cases, such as calculating errors in rotational axes, single error measurement is relatively difficult. Consequently, in production, comprehensive error is adopted to measure attitude errors that are not as accurate [4] to [6].

Based on the double ball bar (DBB) invented by Bryan [7], scholars began to explore its application to the geometric error measurement of rotational axes of computer numerical controlled (CNC) machine tools. Tsutsumi and Saito [8] proposed a method of error measurement and identification based on DBB. Two translational and one rotational, axes were combined into a measurement unit, and the sensitive direction of the DBB is kept constant. Then, four displacement errors and four angular errors of the rotational axes of a CNC machine tool with two turntables were identified. After that, Tsutsumi and Saito [9] proposed a two-step error measurement process and identification model according to the characteristics of a multi-axis control machine tool. Thus, four displacement errors and four angular errors of the rotational axes of the machine tool were obtained. Aiming at the turntable, Chen et al. [10] put forward a method with which to measure the comprehensive geometric errors of the rotational axis by DBB. Two axes were simultaneously controlled, and the circle trajectories were planned in different planes. Hence, there were nine error components measured from three mounting modes. The sources of error in the rotational axis were identified by using the error model. In 
addition, error measurement trajectories were found to influence the efficiency of error identification [11]. Jiang and Cripps [12] established four paths with which to identify the position-independent geometric errors in rotational axes. The displacement errors were measured first and then the angular errors. Chen et al. [13] proposed a four-installation method whereby a DBB was installed parallel to the $X, Y$, and $Z$-axes, and conically. A polynomial model of geometric errors was established, and three displacement errors and two angular errors in the turntable were identified. Compared with the former, this method improves the efficiency of measurement. Zhang et al. [14] planned measurement trajectories of the DBB. Two measurement trajectories of the DBB were designed in different horizontal planes to decouple displacement errors from angular errors. Three displacement errors and two angular errors of the rotational axis were obtained. Based on previous studies, Zhu et al. [15] regarded the $\mathrm{CNC}$ machine tool as a rigid multibody system and presented an integrated geometric error identification model. Six angular errors of the rotational axes on five-axis CNC machine tools with two turntables were identified by using DBB.

With the help of standard parts, the efficiency of the geometric error identification of rotational axes can also be improved. Sharif Uddin et al. [16] proposed a simulator identifying geometric errors of a five-axis machine tool based on DBB. By comparing machining geometric errors generated in machining, a standard workpiece with nominal errors, the geometric errors in a $\mathrm{CNC}$ machine tool with two turntables were identified. Nevertheless, how to select representative standard parts needs further study. Furthermore, analysing the influence of error sources on the end effector is another way to solve the geometric error source identification problem. Lasemi et al. [17] and Ni et al. [18] and [19] divided error sources into position-independent and positiondependent errors according to the difference in the effects of geometric error sources on the end effector by a DBB method. The identification model was established, and the geometric errors were identified by sensitivity analysis.

In addition to DBB, a number of other methods have also been proposed to measure geometric errors. Lei and Hsu [20] developed a device called a probeball. The cutting tool path was defined on a spherical surface, and the overall positioning errors of a fiveaxis CNC machine tool were obtained. However, this device makes it difficult to separate each geometric error in a five-axis machine tool, so it is not easy to use it to measure the geometric errors of the rotational axes. Weikert [21] developed an R-test that consisted of a high-precision ceramic sphere and a pedestal with three or four displacement sensors. By using this device, four geometric errors of the rotational axis on the five-axis $\mathrm{CNC}$ machine tools with two turntables were measured. Although the displacement errors in three directions can be measured simultaneously and more information can be obtained in one test by this device, the manufacturing requirements of the precision sphere are relatively high, which increases the cost of measurement. Similar to the principle of the R-test, the CapBall was developed by Zargarbashi and Mayer [22] which was a kind of measuring device equipped with a non-contact capacitance sensor. In addition to the aforementioned methods, it is feasible to apply a laser to error measurement in rotational axes [23] and [24]. Wang et al. [25] and [26] proposed a method to measure the geometric errors of rotational axes by way of a laser tracker. Based on a sequential multi-lateral measurement principle, the motion trajectories of rotational axes and the space coordinates of each measuring point were measured at different base stations. Then six geometric errors of the rotational axis were identified using the error model. However, the installation and commissioning of the device are slow, and it is expensive.

The research shows that the error measurement and identification of rotational axes on five-axis CNC machine tools are relatively difficult: it is, therefore, necessary to explore a simple and convenient method to measure attitude errors at five-axis machine tools in production sites. In terms of measuring instruments, the DBB is the most widely used due to its low price and simple installation. Here, the $\mathrm{B} / \mathrm{C}$ type of fiveaxis CNC machine tool is studied; the rotational axes are located in the cutting tool movement chain and workpiece movement chain. The geometric error measurement and identification method of the rotational axes with a Renishaw QC-20 DBB are studied. The geometric error sources of two rotational axes on the machine tool are analysed. Then, based on the homogeneous coordinate transformation principle, the mapping relationship between the geometric errors of rotational axes and the structure parameters of the machine tool are established on the $\mathrm{C}$ turntable and $\mathrm{B}$ swinging head. The error identification model for the rotational axes is obtained by changing the installation modes of the DBB in three coordinate directions on the machine tool. Six geometric errors in the rotational axis are identified by using the least-squares method. Finally, the results are verified by way of an error measurement experiment on a machine tool. 


\section{METHODS}

\subsection{Establishment of Coordinate System}

The machine tool shown in Fig. 1 is a B/C type of five-axis CNC machine tool, which consists of three translational axes $(X, Y$, and $Z)$ and two rotational axes (B and $C$ ).

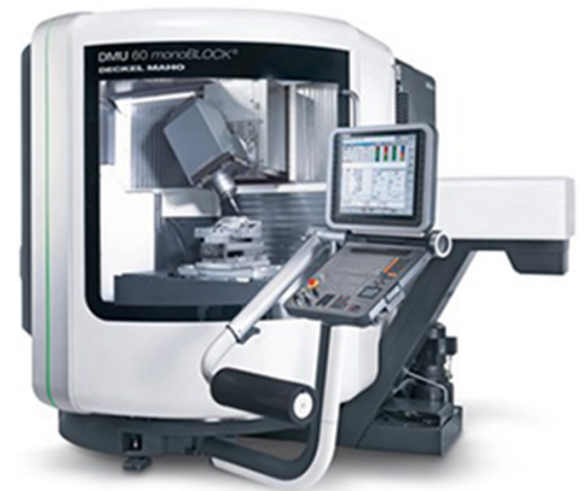

Fig. 1. Five-axis CNC machine tool

According to the kinematic principle, the position of an object in space is described by three translational degrees of freedom (DOFs) and three rotational DOFs of three rectangular coordinate axes in the Cartesian coordinate system. In practical situations, there are six attitude errors in each direction between a kinematic pair of the machine tool. These errors are affected by some factors such as the deviations in the manufacturing, installation, and abrasion of parts.

For the $C$ turntable shown in Fig. 2, when the rotational axis spins, there are errors in the directions of six DOFs, including three displacement errors and three angular errors, which are the displacement error $\delta_{C x}$ in the $X$ direction, the displacement error $\delta_{C y}$ in the $Y$ direction, the displacement error $\delta_{C z}$ in the direction of the $Z$-axis, the angular error $\varepsilon_{C x}$ about the $X$-axis, the angular error $\varepsilon_{C y}$ about the $Y$-axis, and the angular error $\varepsilon_{C z}$ about the $Z$-axis.

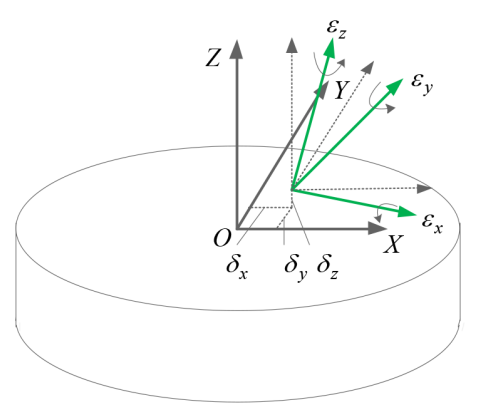

Fig. 2. Six errors of the C turntable
Similarly, for the $B$ swinging head, there are also six errors: the displacement error $\delta_{B x}$ in the $X$ direction, the displacement error $\delta_{B y}$ in the $Y$-axis direction, the displacement error $\delta_{B z}$ in the $Z$ direction, the angular error $\varepsilon_{B x}$ about the $X$-axis, the angular error $\varepsilon_{B y}$ about the $Y$-axis, and the angular error $\varepsilon_{B z}$ about the $Z$-axis.

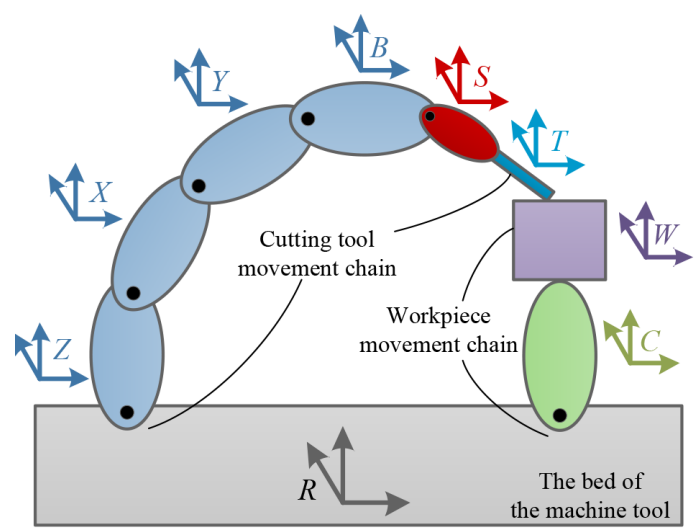

Fig. 3. Partial coordinate system setting of the machine tool

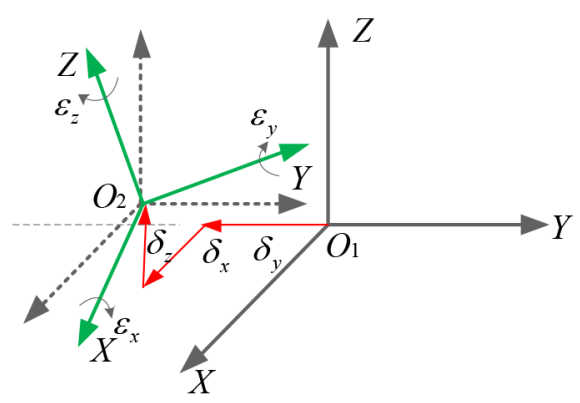

Fig. 4. Schematic representation of the homogeneous coordinate transformation

Ideally, the point of the cutting tool nose is the same as the point to be machined on the workpiece. In reality, there are deviations between them due to the errors in the machine tool. Therefore, the geometric errors are predicted and controlled by establishing the error model for the machine tool. As shown in Fig. 3, there are two transmissions of movement chain from the bed of the machine tool. The cutting tool movement chain is "Bed $\rightarrow Z$-axis $\rightarrow X$-axis $\rightarrow Y$-axis $\rightarrow B$ swinging head $\rightarrow$ Cutting tool". The workpiece movement chain is "Bed $\rightarrow C$ turntable $\rightarrow$ Workpiece". A partial coordinate system is developed for each part of the movement chain on the machine tool. As shown in Fig. 4, $O_{1}-X Y Z$ and $O_{2}-X Y Z$ are coordinate systems fixed on arbitrary adjacent parts. There are both translational and rotation transformations of $O_{2}-X Y Z$ relative to $O_{1}-X Y Z$. For the translational transformation, $O_{2}-X Y Z$ respectively moves through $\delta_{x}, \delta_{y}$, and $\delta_{z}$ in the $X, Y$, and $Z$ directions relative to $O_{1}-X Y Z$. For the rotational 
transformation, $O_{2}-X Y Z$ respectively rotates through $\varepsilon_{x}, \varepsilon_{y}$ and $\varepsilon_{z}$ about the $X, Y$, and $Z$ axes of $O_{1}-X Y Z$.

When $O_{2}-X Y Z$ moves through $\delta_{x}$ only along the direction of the $X$-axis of $O_{1}-X Y Z$, the homogeneous coordinate transformation of $\mathrm{O}_{2}-X Y Z$ relative to $O_{1}-X Y Z$ is:

$$
\boldsymbol{T}_{x}=\left(\begin{array}{cccc}
1 & 0 & 0 & \delta_{x} \\
0 & 1 & 0 & 0 \\
0 & 0 & 1 & 0 \\
0 & 0 & 0 & 1
\end{array}\right)
$$

Similarly, $\boldsymbol{T}_{y}$ and $\boldsymbol{T}_{z}$ are available.

When $O_{2}-X Y Z$ rotates through $\varepsilon_{x}$ only about the $X$-axis of $O_{1}-X Y Z$, the homogeneous coordinate transformation of $O_{2}-X Y Z$ relative to $O_{1}-X Y Z$ is:

$$
\boldsymbol{R}_{x}=\left(\begin{array}{cccc}
1 & 0 & 0 & 0 \\
0 & \cos \varepsilon_{x} & -\sin \varepsilon_{x} & 0 \\
0 & \sin \varepsilon_{x} & \cos \varepsilon_{x} & 0 \\
0 & 0 & 0 & 1
\end{array}\right) .
$$

Similarly, $\boldsymbol{R}_{y}$ and $\boldsymbol{R}_{y}$ are available.

The error can be interpreted as a small perturbation and a first-order linear approximation at the point of measurement. Thus, the approximate relationships are

$$
\begin{gathered}
\sin \Delta \alpha \approx \Delta \alpha, \\
\cos \Delta \alpha \approx 1,
\end{gathered}
$$

where $\Delta \alpha$ is a variable that can be replaced by $\delta_{x}$, $\delta_{y}, \delta_{z}, \varepsilon_{x}, \varepsilon_{y}$, and $\varepsilon_{z}$. Because of the multiplication of variables, there will be higher-order infinitesimals. The higher-order parts are omitted, and only the firstorder variables remain; therefore, the homogeneous coordinate transformation of $\mathrm{O}_{2}-X Y Z$ relative to $O_{1}-X Y Z$ is

$$
\begin{aligned}
\boldsymbol{T} & =\boldsymbol{T}_{x} \cdot \boldsymbol{T}_{y} \cdot \boldsymbol{T}_{z} \cdot \boldsymbol{R}_{x} \cdot \boldsymbol{R}_{y} \cdot \boldsymbol{R}_{z} \\
& =\left(\begin{array}{cccc}
1 & -\varepsilon_{z} & \varepsilon_{y} & \delta_{x} \\
\varepsilon_{z} & 1 & -\varepsilon_{x} & \delta_{y} \\
-\varepsilon_{y} & \varepsilon_{x} & 1 & \delta_{z} \\
0 & 0 & 0 & 1
\end{array}\right) .
\end{aligned}
$$

\subsection{Geometric Error Identification Model}

The DBB is used as the measuring instrument; it is a Renishaw QC20-W. It is used in connection with the lengthening bar of different sizes. The measurement accuracy of the DBB is $\pm 1.25 \mu \mathrm{m}$.

The geometric errors of each axis are obtained by changing the installation positions of the DBB. The identification model is established in the measuring mode of the DBB to acquire the geometric errors in each axis.

\subsubsection{Identification Model on the C Turntable}

As shown in Fig. 5, the DBB is installed parallel to the $X$-axis. One end is connected with the spindle, and the other end is fixed on the machine tool table. A fixed coordinate system is developed, and it is assumed that the coordinate origin is the intersection point of the surface and the rotational axis of the $C$ turntable; $L$ is the distance between the centre $P$ and the rotational axis of the $C$ turntable, and $H$ represents the distance between the centre $P$ and the surface of the $C$ turntable in the $Z$-direction. In the initial state, the homogeneous coordinate of the point $P$ in the fixed coordinate system can be expressed by $P=\left(\begin{array}{llll}L & 0 & H & 1\end{array}\right)^{T}$.

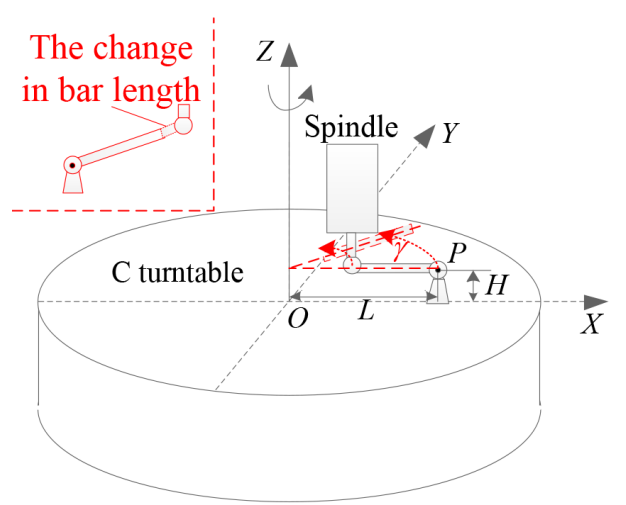

Fig. 5. Installation of the DBB of the $C$ turntable

Under ideal conditions, when the rotation angle of the $C$ turntable about the $Z$-axis is $\gamma$, the coordinates of point $P$ can be expressed by:

$$
P_{i}={ }^{i} \boldsymbol{T}_{C}^{R} \cdot P=\left(\begin{array}{llll}
L \cos \gamma & L \sin \gamma & H & 1
\end{array}\right)^{\mathrm{T}},
$$

where ${ }^{i} \boldsymbol{T}_{C}^{R}=\left(\begin{array}{cccc}\cos \gamma & -\sin \gamma & 0 & 0 \\ \sin \gamma & \cos \gamma & 0 & 0 \\ 0 & 0 & 1 & 0 \\ 0 & 0 & 0 & 1\end{array}\right)$ is the coordinate transformation matrix used to move from coordinate system $C$ fixed on the $C$ turntable to the reference coordinate system $R$ fixed on the bed of the machine tool. The superscript $i$ denotes the $i^{\text {th }}$ position of the $C$ turntable during measurement.

When the $C$ turntable moves, there are three displacement errors: $\delta_{C x}, \delta_{C y}$ and $\delta_{C z}$ along the $X, Y$, and $Z$ directions and three angular errors $\varepsilon_{C X}, \varepsilon_{C y}$ and $\varepsilon_{C Z}$ about the $X, Y$, and $Z$ axis. Based on the theoretical 
derivation of Eq. (5), the error matrix generated by the rotation of the $C$ turntable is:

$$
\boldsymbol{E}_{C}^{R}=\left(\begin{array}{cccc}
1 & -\varepsilon_{C z} & \varepsilon_{C y} & \delta_{C x} \\
\varepsilon_{C z} & 1 & -\varepsilon_{C x} & \delta_{C y} \\
-\varepsilon_{C y} & \varepsilon_{C x} & 1 & \delta_{C z} \\
0 & 0 & 0 & 1
\end{array}\right) .
$$

Due to the existence of these errors, point $P$ is not in its ideal position and its actual coordinates can be expressed by:

$$
\begin{aligned}
P_{e} & =\boldsymbol{E}_{C}^{R} \cdot{ }^{i} \boldsymbol{T}_{C}^{R} \cdot P \\
& =\left(\begin{array}{c}
L\left(\cos \gamma-\sin \gamma \cdot \varepsilon_{C z}\right)+H \cdot \varepsilon_{C y}+\delta_{C x} \\
L\left(\cos \gamma \cdot \varepsilon_{C z}+\sin \gamma\right)-H \cdot \varepsilon_{C x}+\delta_{C y} \\
L\left(-\cos \gamma \cdot \varepsilon_{C y}+\sin \gamma \cdot \varepsilon_{C x}\right)+H+\delta_{C z} \\
1
\end{array}\right) .
\end{aligned}
$$

The difference between the actual and theoretical coordinates of point $P$ can be expressed by:

$$
\begin{aligned}
\Delta P & =P_{e}-P_{i} \\
& =\left(\begin{array}{c}
-L \sin \gamma \cdot \varepsilon_{C z}+H \varepsilon_{C y}+\delta_{C x} \\
L \varepsilon_{C z} \cdot \cos \gamma-H \varepsilon_{C x}+\delta_{C y} \\
L\left(-\varepsilon_{C y} \cdot \cos \gamma+\varepsilon_{C x} \cdot \sin \gamma\right)+\delta_{C z} \\
0
\end{array}\right)=\left(\begin{array}{c}
\Delta X \\
\Delta Y \\
\Delta Z \\
0
\end{array}\right) .
\end{aligned}
$$

where $\Delta X, \Delta Y$ and $\Delta Z$ are the components in three coordinate directions of the changes in bar length.

From Eq. (9), six errors in the $C$ turntable can be obtained indirectly by measuring the value of $\triangle P$. To acquire $\Delta X, \Delta Y$ and $\Delta Z$ in Eq. (9), the DBB needs to be installed separately in the radial, axial, and tangential directions. To improve the accuracy of identification, the values of $H$ and $L$ need to be changed to obtain the errors in the $X, Y$, and $Z$ directions using different installation methods. Therefore, six geometric errors generated during the rotation motion of the $C$ turntable can be identified.

\subsubsection{The First Combination Method}

When the DBB is installed parallel to the $X$-axis (radial installation) or $Y$-axis (tangential installation):

$$
L=L_{1} \text {. }
$$

When the DBB is installed parallel to the $Z$-axis (axial installation):

$$
L=0 .
$$

In the two installation methods, $H_{1}$ is the value of $H$ when the DBB is directly installed on the worktable.
The schematic diagrams of this type of combination are illustrated in Figs 6 and 7.

Eq. (9) can be written as:

$$
\left(\begin{array}{c}
-L_{1} \sin \gamma_{i} \cdot \varepsilon_{C z i}+H_{1} \varepsilon_{C y i}+\delta_{C x i} \\
L_{1} \varepsilon_{C z i} \cdot \cos \gamma_{i}-H_{1} \varepsilon_{C x i}+\delta_{C y i} \\
L_{1}\left(-\varepsilon_{C y i} \cdot \cos \gamma_{i}+\varepsilon_{C x i} \cdot \sin \gamma_{i}\right)+\delta_{C z i}
\end{array}\right)=\left(\begin{array}{c}
\Delta X_{1 i} \\
\Delta Y_{1 i} \\
\Delta Z_{1 i}
\end{array}\right) \text {. }
$$

Where $\gamma_{i}$ is the rotation angle of the $C$ turntable and subscript $i$ denotes the $i^{\text {th }}$ measurement point. $\delta_{C x i}, \delta_{C y i}, \delta_{C z i}, \varepsilon_{C x i}, \varepsilon_{C y i}, \varepsilon_{C z i}$ are the geometric errors corresponding to the $C$ turntable at rotation angle $\gamma_{i}$. $\Delta X_{1 i}, \Delta Y_{1 i}$ and $\Delta Z_{1 i}$ are the differences between the actual and the theoretical coordinates of point $P$ in the $X, Y$, and $Z$ directions when the rotation angle is $\gamma_{i}$. The following meanings are the same as those indicated by the above symbols.

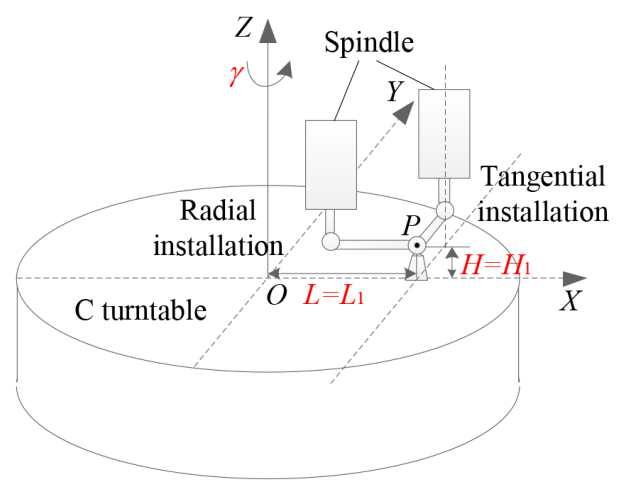

Fig. 6. First combination: radial and tangential installations

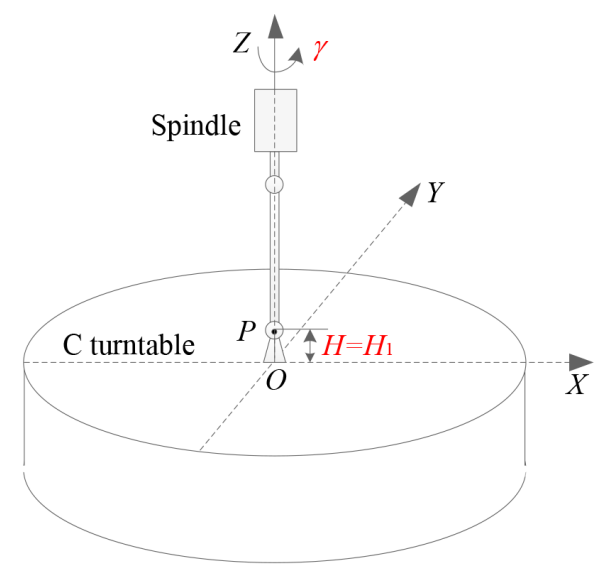

Fig. 7. First combination: axial installation

$\Delta X_{1 i}$ and $\Delta Y_{1 i}$ can be obtained by the changes $\Delta l_{r 1 i}$ and $\Delta l_{t 1 i}$ in bar length when the DBB is installed in radial and tangential directions. They can be expressed by:

$$
\left(\begin{array}{l}
\Delta X_{1 i} \\
\Delta Y_{1 i}
\end{array}\right)=\left(\begin{array}{c}
\Delta l_{r 1 i} \cdot \cos \gamma_{i}-\Delta l_{t 1 i} \cdot \sin \gamma_{i} \\
\Delta l_{r 1 i} \cdot \sin \gamma_{i}+\Delta l_{t 1 i} \cdot \cos \gamma_{i}
\end{array}\right)
$$


$\Delta Z_{1 i}$ is the change in bar length when the DBB is installed in the axial direction, where $\Delta Z_{1 i}=\Delta l_{a 1 i}$.

Eq. (12) can be written as:

$$
\begin{gathered}
\left(\begin{array}{c}
-L_{1} \sin \gamma_{i} \cdot \varepsilon_{C z i}+H_{1} \varepsilon_{C y i}+\delta_{C x i} \\
L_{1} \varepsilon_{C z i} \cdot \cos \gamma_{i}-H_{1} \varepsilon_{C x i}+\delta_{C y i} \\
\delta_{C z i}
\end{array}\right)= \\
\left(\begin{array}{c}
\Delta l_{r 1 i} \cdot \cos \gamma_{i}-\Delta l_{t 1 i} \cdot \sin \gamma_{i} \\
\Delta l_{r 1 i} \cdot \sin \gamma_{i}+\Delta l_{t 1 i} \cdot \cos \gamma_{i} \\
\Delta l_{a 1 i}
\end{array}\right) .
\end{gathered}
$$

\subsubsection{The Second Combination Method}

When the DBB is installed parallel to the $X$-axis (radial installation) or $Y$-axis (tangential installation):

$$
\begin{gathered}
L=L_{2}, L_{2} \neq L_{1}, \\
H=H_{2}, H_{2}=H_{1} .
\end{gathered}
$$

As $\delta_{C z i}$ can be directly obtained under the first combination, the installation method parallel to the $Z$-axis is unnecessary. The schematic diagram of this type of combination is illustrated in Fig. 8.

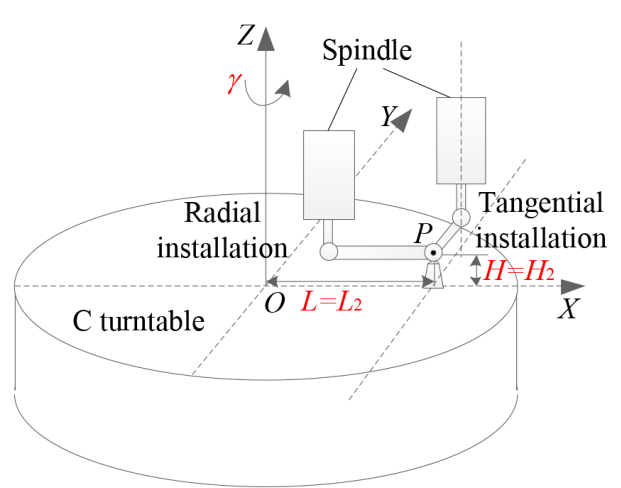

Fig. 8. Second combination: radial and tangential installations

Eq. (9) can be written as:

$$
\left(\begin{array}{c}
-L_{2} \sin \gamma_{i} \cdot \varepsilon_{C z i}+H_{2} \varepsilon_{C y i}+\delta_{C x i} \\
L_{2} \varepsilon_{C z i} \cdot \cos \gamma_{i}-H_{2} \varepsilon_{C x i}+\delta_{C y i}
\end{array}\right)=\left(\begin{array}{l}
\Delta X_{2 i} \\
\Delta Y_{2 i}
\end{array}\right) .
$$

Similarly, $\Delta X_{2 i}$ and $\Delta Y_{2 i}$ can be obtained by the changes $\Delta l_{r 2 i}$ and $\Delta l_{t 2 i}$ in bar length when the DBB is installed in the radial and tangential directions. They can be expressed by:

$$
\left(\begin{array}{l}
\Delta X_{2 i} \\
\Delta Y_{2 i}
\end{array}\right)=\left(\begin{array}{l}
\Delta l_{r 2 i} \cdot \cos \gamma_{i}-\Delta l_{t 2 i} \cdot \sin \gamma_{i} \\
\Delta l_{r 2 i} \cdot \sin \gamma_{i}+\Delta l_{t 2 i} \cdot \cos \gamma_{i}
\end{array}\right) .
$$

Eq. (17) can be written as:

$$
\begin{gathered}
\left(\begin{array}{c}
-L_{2} \sin \gamma_{i} \cdot \varepsilon_{C z i}+H_{2} \varepsilon_{C y i}+\delta_{C x i} \\
L_{2} \varepsilon_{C z i} \cdot \cos \gamma_{i}-H_{2} \varepsilon_{C x i}+\delta_{C y i}
\end{array}\right) \\
=\left(\begin{array}{c}
\Delta l_{r 2 i} \cdot \cos \gamma_{i}-\Delta l_{t 2 i} \cdot \sin \gamma_{i} \\
\Delta l_{r 2 i} \cdot \sin \gamma_{i}+\Delta l_{t 2 i} \cdot \cos \gamma_{i}
\end{array}\right) .
\end{gathered}
$$

\subsubsection{The Third Combination Method}

When the DBB is installed parallel to the $X$-axis (radial installation) or $Y$-axis (tangential installation), gives:

$$
\begin{gathered}
L=L_{3}, L_{3}=L_{1}, \\
H=H_{3}, H_{3} \neq H_{1}
\end{gathered}
$$

$H_{3}$ is the value of $H$ based on $H_{1}$ when a magnetic fixture or a cushion block is added between the DBB and the worktable. The schematic diagram of this type of combination is shown in Fig. 9.

Eq. (9) can be written as:

$$
\left(\begin{array}{c}
-L_{3} \sin \gamma_{i} \cdot \varepsilon_{C z i}+H_{3} \varepsilon_{C y i}+\delta_{C x i} \\
L_{3} \varepsilon_{C z i} \cdot \cos \gamma_{i}-H_{3} \varepsilon_{C x i}+\delta_{C y i}
\end{array}\right)=\left(\begin{array}{c}
\Delta X_{3 i} \\
\Delta Y_{3 i}
\end{array}\right) .
$$

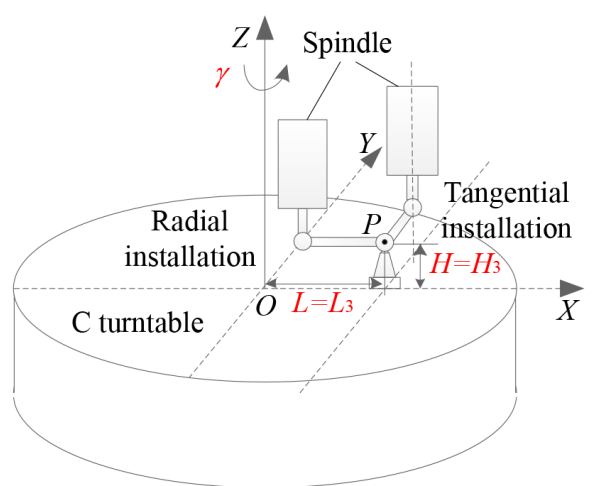

Fig. 9. Third combination: radial and tangential installations

Similarly, $\Delta X_{3 i}$ and $\Delta Y_{3 i}$ can be obtained from the changes $\Delta l_{r 3 i}$ and $\Delta l_{t 3 i}$ in bar length when the DBB is installed in the radial and tangential directions. They can be written as:

$$
\left(\begin{array}{c}
\Delta X_{3 i} \\
\Delta Y_{3 i}
\end{array}\right)=\left(\begin{array}{c}
\Delta l_{r 3 i} \cdot \cos \gamma_{i}-\Delta l_{t 3 i} \cdot \sin \gamma_{i} \\
\Delta l_{r 3 i} \cdot \sin \gamma_{i}+\Delta l_{t 3 i} \cdot \cos \gamma_{i}
\end{array}\right)
$$

Eq. (22) can be written as:

$$
\begin{gathered}
\left(\begin{array}{c}
-L_{3} \sin \gamma_{i} \cdot \varepsilon_{C z i}+H_{3} \varepsilon_{C y i}+\delta_{C x i} \\
L_{3} \varepsilon_{C z i} \cdot \cos \gamma_{i}-H_{3} \varepsilon_{C x i}+\delta_{C y i}
\end{array}\right) \\
=\left(\begin{array}{c}
\Delta l_{r 3 i} \cdot \cos \gamma_{i}-\Delta l_{t 3 i} \cdot \sin \gamma_{i} \\
\Delta l_{r 3 i} \cdot \sin \gamma_{i}+\Delta l_{t 3 i} \cdot \cos \gamma_{i}
\end{array}\right) .
\end{gathered}
$$

Therefore, six geometric errors at any angle can be calculated from Eqs. (14), (19), and (24). 


\subsubsection{Identification Model for the B Swinging Head}

As shown in Fig. 10, the spindle of the machine tool is placed in the vertical direction. The DBB is installed parallel to the $Y$-axis. One end is connected with the spindle, and the other end is fixed on the machine tool table. The fixed coordinate system is established as shown in the figure. It was assumed that the coordinate origin was the intersection point of the swinging axis of the $B$ swinging head and spindle axis. $L$ is the distance between the centre $P$ and the swinging axis of the $B$ swinging head in the $Z$-direction. In its initial state, the homogeneous coordinates of point $P$ in the fixed coordinate system can be expressed by $P=\left(\begin{array}{llll}0 & 0 & -L & 1\end{array}\right)^{T}$.

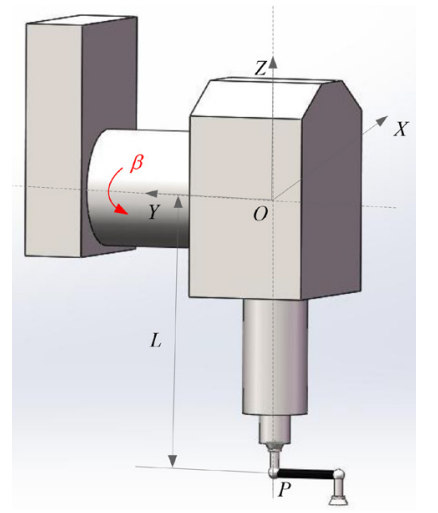

Fig. 10. Installation method of the $D B B$ on the $B$ swinging head

Under ideal conditions, when the rotation angle of the $B$ swinging head about the $Y$-axis is $\beta$, the coordinates of point $P$ can be expressed by:

$$
P_{i}={ }^{i} \boldsymbol{T}_{B}^{R} \cdot P=\left(\begin{array}{llll}
L \sin \beta & 0 & L \cos \beta & 1
\end{array}\right)^{\mathrm{T}},
$$

where ${ }^{i} \boldsymbol{T}_{B}^{R}=\left(\begin{array}{cccc}\cos \beta & 0 & \sin \beta & 0 \\ 0 & 1 & 0 & 0 \\ -\sin \beta & 0 & \cos \beta & 0 \\ 0 & 0 & 0 & 1\end{array}\right)$.

When the $B$ swinging head moves, there are three displacement errors: $\delta_{B x}, \delta_{B y}$ and $\delta_{B z}$ along the $X, Y$, and $Z$ direction and three angular errors $\varepsilon_{B x}, \varepsilon_{B y}, \varepsilon_{B z}$ about the $X, Y$, and $Z$ axes. The error matrix generated by the rotation of the $B$ swinging head is:

$$
\boldsymbol{E}_{B}^{R}=\left(\begin{array}{cccc}
1 & -\varepsilon_{B z} & \varepsilon_{B y} & \delta_{B x} \\
\varepsilon_{B z} & 1 & -\varepsilon_{B x} & \delta_{B y} \\
-\varepsilon_{B y} & \varepsilon_{B x} & 1 & \delta_{B z} \\
0 & 0 & 0 & 1
\end{array}\right) .
$$

Because of the existence of errors, the actual coordinates of point $P$ can be expressed by:

$$
P_{e}=\boldsymbol{E}_{B}^{R} \cdot{ }^{i} \boldsymbol{T}_{B}^{R} \cdot P=\left(\begin{array}{c}
L\left(\sin \beta+\varepsilon_{B y} \cos \beta\right)+\delta_{B x} \\
L\left(\varepsilon_{B z} \sin \beta-\varepsilon_{B x} \cos \beta\right)+\delta_{B y} \\
L\left(-\varepsilon_{B y} \sin \beta+\cos \beta\right)+\delta_{B z} \\
1
\end{array}\right) .
$$

The difference between the actual, and theoretical, coordinates of point $P$ can be obtained as:

$$
\left.\begin{array}{l}
\Delta P=P_{e}-P_{i} \\
L \varepsilon_{B y} \cos \beta+\delta_{B x} \\
L\left(\varepsilon_{B z} \sin \beta-\varepsilon_{B x} \cos \beta\right)+\delta_{B y} \\
-L \varepsilon_{B y} \sin \beta+\delta_{B z} \\
0
\end{array}\right)=\left(\begin{array}{c}
\Delta X \\
\Delta Y \\
\Delta Z \\
0
\end{array}\right) .
$$

From Eq. (28), six errors in the $B$ swinging head can be obtained indirectly by solving the value of $\triangle P$. To obtain $\Delta X, \Delta Y$ and $\Delta Z$ in Eq. (28), the DBB needs to be installed separately in the radial, tangential, and axial directions. To improve the accuracy of identification, the value of $L$ needs to be changed to solve the error values in the $X, Y$, and $Z$ directions under different DBB installation methods. Therefore, the geometric errors generated during the rotation motion of the $B$ swinging head can be identified.

\subsubsection{The First Combination Method}

When the DBB is installed parallel to the $X$-axis (tangential installation), $Z$-axis (radial installation), or $Y$-axis (axial installation):

$$
L=L_{1} .
$$

Schematic representations of this type of combination are demonstrated in Figs. 11 and 12.

Eq. (28) can be written as:

$$
\left(\begin{array}{c}
L_{1} \varepsilon_{B y i} \cos \beta_{i}+\delta_{B x i} \\
L_{1}\left(\varepsilon_{B z i} \sin \beta_{i}-\varepsilon_{B x i} \cos \beta_{i}\right)+\delta_{B y i} \\
-L_{1} \varepsilon_{B y i} \sin \beta_{i}+\delta_{B z i}
\end{array}\right)=\left(\begin{array}{c}
\Delta X_{1 i} \\
\Delta Y_{1 i} \\
\Delta Z_{1 i}
\end{array}\right),
$$

where $\beta_{i}$ is the rotation angle of the $B$ swinging head, $\delta_{B x i}, \delta_{B y i}, \delta_{B z i}, \varepsilon_{B x i}, \varepsilon_{B y i}$ and $\varepsilon_{B z i}$ are the geometric errors corresponding to the $B$ swinging head when the rotation angle is $\beta_{i} ; \Delta X_{1 i}, \Delta Y_{1 i}$, and $\Delta Z_{1 i}$ are the differences between the actual and the theoretical coordinates of point $P$ in the $X, Y$, and $Z$ directions when the rotation angle is $\beta_{i}$. Subscript $i$ denotes the $i^{\text {th }}$ measurement point. The following meanings are the same as the above symbols.

$\Delta X_{1 i}$ and $\Delta Z_{1 i}$ can be obtained from the changes $\Delta l_{r 1 i}$ and $\Delta l_{t 1 i}$ in bar length when the DBB is installed in the radial and tangential directions. They can be expressed by: 


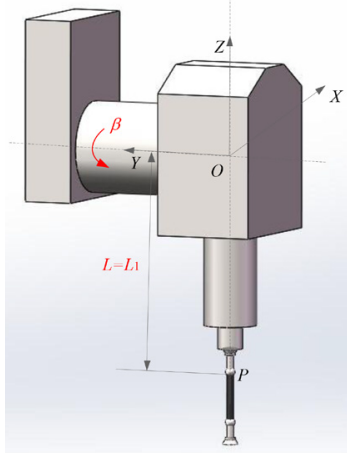

Fig. 11. First combination: radial installation

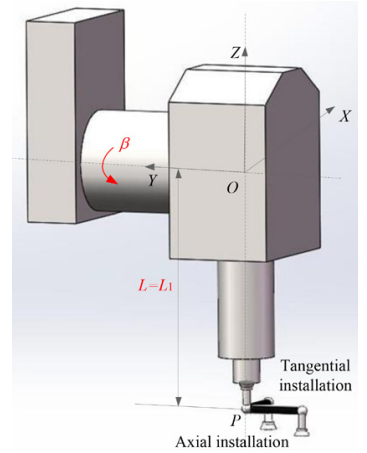

Fig. 12. First combination: axial and tangential installations

$$
\left(\begin{array}{l}
\Delta X_{1 i} \\
\Delta Z_{1 i}
\end{array}\right)=\left(\begin{array}{c}
\Delta l_{r l i} \cdot \cos \gamma_{i}-\Delta l_{t l i} \cdot \sin \gamma_{i} \\
\Delta l_{r l i} \cdot \sin \gamma_{i}+\Delta l_{t i i} \cdot \cos \gamma_{i}
\end{array}\right) .
$$

$\Delta Y_{1 i}$ is the change in bar length when the DBB is installed in the axial direction where $\Delta Y_{1 i}=\Delta l_{a 1 i}$.

Eq. (30) can be written as:

$$
\begin{gathered}
\left(\begin{array}{c}
L_{1} \varepsilon_{B y i} \cos \beta_{i}+\delta_{B x i} \\
L_{1}\left(\varepsilon_{B z i} \sin \beta_{i}-\varepsilon_{B x i} \cos \beta_{i}\right)+\delta_{B y i} \\
-L_{1} \varepsilon_{B y i} \sin \beta_{i}+\delta_{B z i}
\end{array}\right) \\
=\left(\begin{array}{c}
\Delta l_{r 1 i} \cdot \cos \gamma_{i}-\Delta l_{t l i} \cdot \sin \gamma_{i} \\
\Delta l_{a l i} \\
\Delta l_{r l i} \cdot \sin \gamma_{i}+\Delta l_{t l i} \cdot \cos \gamma_{i}
\end{array}\right) .
\end{gathered}
$$

\subsubsection{The Second Combination Method}

When the DBB is installed parallel to the $X$-axis (tangential installation), $Z$-axis (radial installation), or $Y$-axis (axial installation):

$$
L=L_{2}, L_{2} \neq L_{1} .
$$

The schematic representations of these types of combination are shown in Figs. 13 and 14.

Eq. (28) can be written as:

$$
\left(\begin{array}{c}
L_{2} \varepsilon_{B y i} \cos \beta_{i}+\delta_{B x i} \\
L_{2}\left(\varepsilon_{B z i} \sin \beta_{i}-\varepsilon_{B x i} \cos \beta_{i}\right)+\delta_{B y i} \\
-L_{2} \varepsilon_{B y i} \sin \beta_{i}+\delta_{B z i}
\end{array}\right)=\left(\begin{array}{c}
\Delta X_{2 i} \\
\Delta Y_{2 i} \\
\Delta Z_{2 i}
\end{array}\right) .
$$

Similarly, $\Delta X_{2 i}$ and $\Delta Z_{2 i}$ can be calculated from the changes $\Delta l_{r 2 i}$ and $\Delta l_{t 2 i}$ in bar length when the DBB is installed in the radial and tangential directions. They can be expressed by:

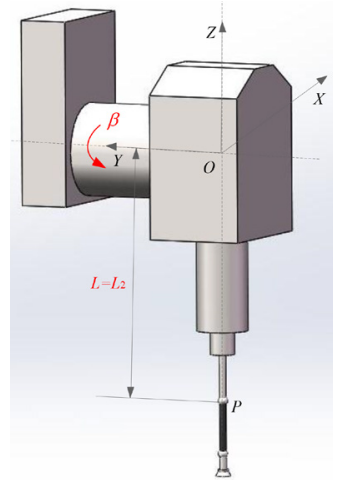

Fig. 13. Second combination: radial installation

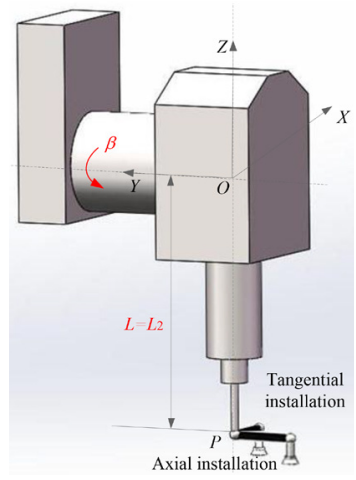

Fig. 14. Second combination: axial and tangential installations

$$
\left(\begin{array}{l}
\Delta X_{2 i} \\
\Delta Z_{2 i}
\end{array}\right)=\left(\begin{array}{l}
\Delta l_{r 2 i} \cdot \cos \gamma_{i}-\Delta l_{t 2 i} \cdot \sin \gamma_{i} \\
\Delta l_{r 2 i} \cdot \sin \gamma_{i}+\Delta l_{t 2 i} \cdot \cos \gamma_{i}
\end{array}\right) .
$$

$\Delta Y_{2 i}$ is the change in bar length when the DBB is installed in the axial direction where $\Delta Y_{2 i}=\Delta l_{a 2 i}$.

Eq. (34) can be written as:

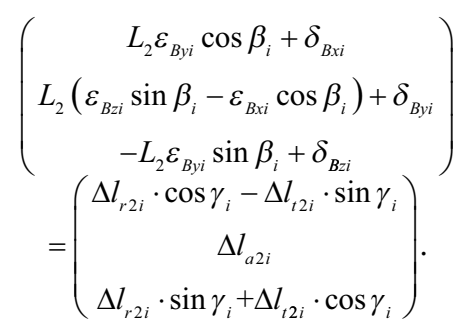

Therefore, six geometric errors, at any angle of the $B$ axis, can be calculated from Eqs. (32) and (36).

\section{EXPERIMENT AND RESULTS}

\subsection{Error Measurement Experiment: The Rotational Axis}

The parameters of the machine tool are as follows: the rotation angle range of the $C$ turntable is $0^{\circ}$ to $360^{\circ}$, and the swinging angle range of the $B$ swinging head is $-120^{\circ}$ to $30^{\circ}$. The displacement errors in the $B$ axis and $C$ axis are measured under different installations in the $X, Y$, and $Z$ directions by the DBB when they are rotated through different angles. The error measurements on the $C$ axis and the $B$ axis are shown in Figs. 15 and 16. Six geometric errors of each axis are calculated by use of the identification model. In the process of the experiment, the bar length of the DBB is $150 \mathrm{~mm}$. The rotation angle of the $C$ turntable is $0^{\circ}$ to $360^{\circ}$ and the rotation interval is $20^{\circ}$. The swinging angle of the $B$ axis is $-100^{\circ}$ to $0^{\circ}$ and 

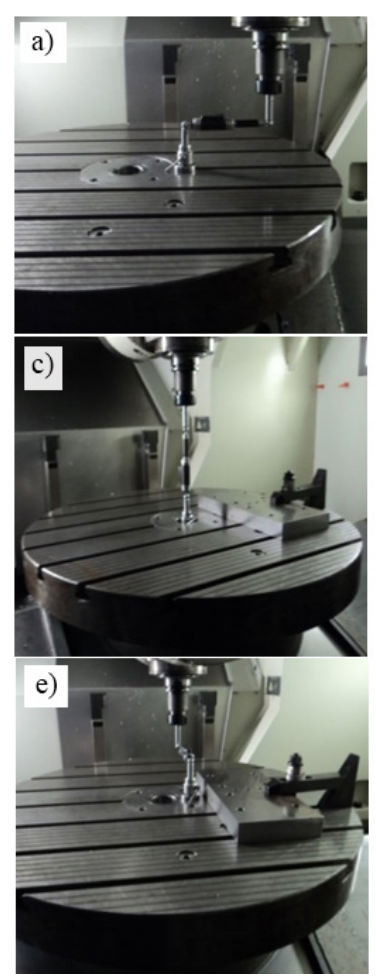

Fig. 15. The measurement on the $\mathrm{C}$ axis
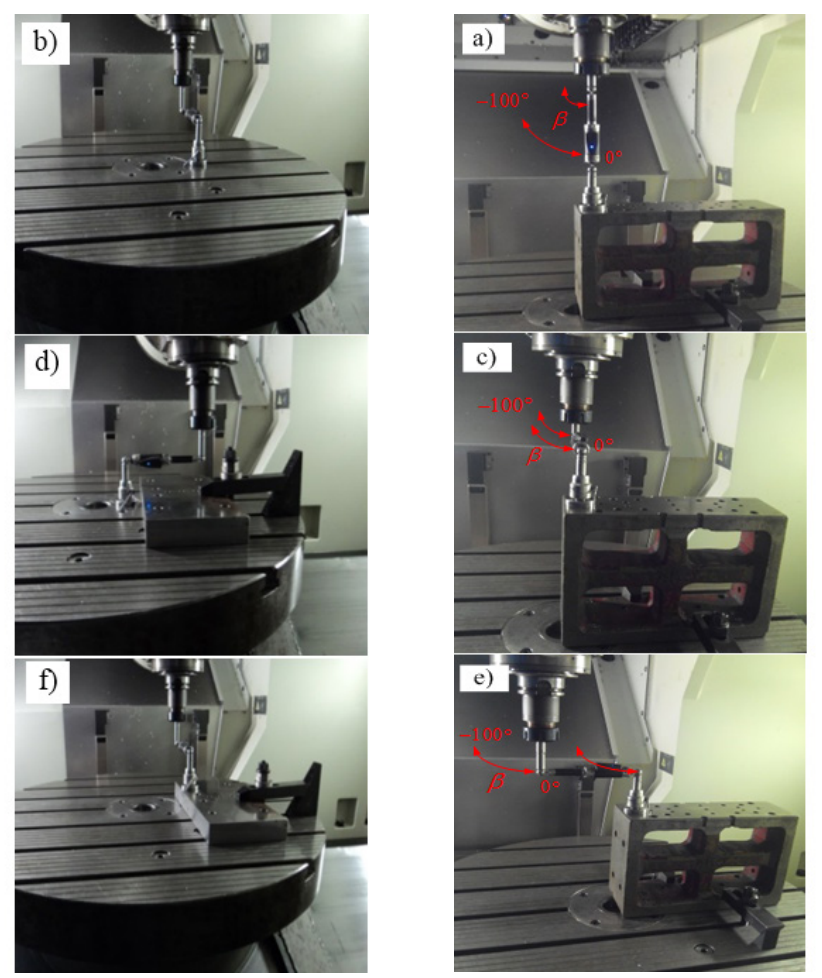

Fig. 16. The measurement on the $B$ axis
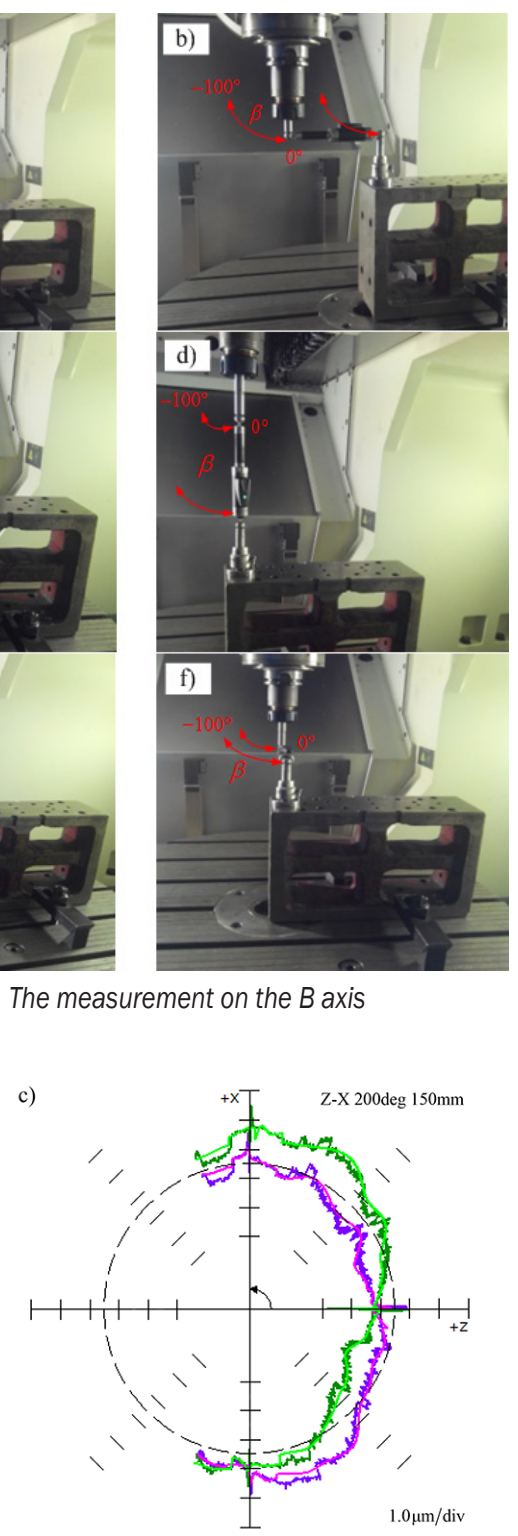
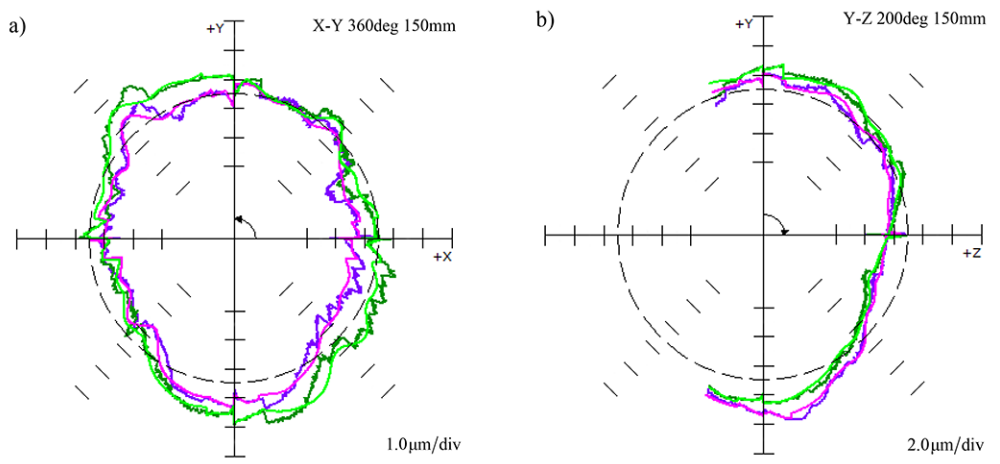

Fig. 17. The experimental results of the translational axes in three planes

the rotation interval is $5^{\circ}$. The errors are measured three times in each direction (clockwise and counter clockwise).

The geometric errors of the translational axes can be directly measured by the DBB and analysed with the Ballbar20 software. The measurements are conducted in the $X-Y$ plane, $Y-Z$ plane, and $X-Z$ plane separately. The results of the errors are shown in Fig. 17, according to which the following analyses can be obtained.

$X$-axis: The backlash errors are $0.2 \mu \mathrm{m}$ in the forward direction and $0.1 \mu \mathrm{m}$ in the reverse direction. The straightness error is $-1.5 \mu \mathrm{m}$.
$Y$-axis: The backlash errors are is $-0.1 \mu \mathrm{m}$ in the forward direction and is $-0.2 \mu \mathrm{m}$ in the reverse direction. The straightness error is $-2.5 \mu \mathrm{m}$.

$Z$-axis: The backlash errors are $0.4 \mu \mathrm{m}$ in the forward direction. The straightness error cannot be analysed by the software because of the partial circle measurement. It can be measured by other methods.

The squareness error between the $X$-axis and the $Y$-axis is $11.2 \mu \mathrm{m} / \mathrm{m}$. The squareness error between the $Y$-axis and the $Z$-axis is $10.7 \mu \mathrm{m} / \mathrm{m}$. The squareness error between the $Z$-axis and the $X$-axis is $12.1 \mu \mathrm{m} / \mathrm{m}$.

The roundness errors are $6.1 \mu \mathrm{m}, 8.6 \mu \mathrm{m}$, and $7.4 \mu \mathrm{m}$ in Fig. 17, respectively. Thus, there are 
Table 1. The change values $\Delta l$ of $D B B$ bar length when measuring $C$ turntable

\begin{tabular}{|c|c|c|c|c|c|c|c|}
\hline \multirow{2}{*}{ Angles [ $\left.{ }^{0}\right]$} & \multicolumn{3}{|c|}{$\Delta l_{1}[\mathrm{~mm}]$} & \multicolumn{2}{|c|}{$\Delta l_{2}[\mathrm{~mm}]$} & \multicolumn{2}{|c|}{$\Delta l_{3}[\mathrm{~mm}]$} \\
\hline & Radial & Tangential & Axial & Radial & Tangential & Radial & Tangentia \\
\hline 0 & -0.0002 & 0.0082 & 0.0143 & -0.0148 & 0.0040 & 0.0017 & 0.0061 \\
\hline 20 & 0.0522 & 0.0032 & 0.0140 & 0.0379 & 0.0018 & 0.0530 & 0.0023 \\
\hline 40 & 0.1005 & 0.0174 & 0.0140 & 0.0856 & 0.0179 & 0.1025 & 0.0163 \\
\hline 60 & 0.1433 & 0.0485 & 0.0140 & 0.1271 & 0.0512 & 0.1427 & 0.0487 \\
\hline 80 & 0.1698 & 0.0915 & 0.0142 & 0.1519 & 0.0953 & 0.1704 & 0.0922 \\
\hline 100 & 0.1799 & 0.1411 & 0.0142 & 0.1599 & 0.1457 & 0.1804 & 0.1421 \\
\hline 120 & 0.1741 & 0.1913 & 0.0143 & 0.1526 & 0.1957 & 0.1725 & 0.1921 \\
\hline 140 & 0.1510 & 0.2378 & 0.0143 & 0.1275 & 0.2408 & 0.1492 & 0.2373 \\
\hline 160 & 0.1134 & 0.2715 & 0.0144 & 0.0879 & 0.2732 & 0.1112 & 0.2708 \\
\hline 180 & 0.0663 & 0.2910 & 0.0142 & 0.0403 & 0.2903 & 0.0647 & 0.2896 \\
\hline 200 & 0.0180 & 0.2934 & 0.0142 & -0.0086 & 0.2910 & 0.0154 & 0.2907 \\
\hline 220 & -0.0283 & 0.2783 & 0.0141 & -0.0541 & 0.2732 & -0.0310 & 0.2747 \\
\hline 240 & -0.0686 & 0.2482 & 0.0142 & -0.0933 & 0.2417 & -0.0702 & 0.2439 \\
\hline 260 & -0.0967 & 0.2069 & 0.0141 & -0.1196 & 0.1992 & -0.0982 & 0.2020 \\
\hline 280 & -0.1105 & 0.1604 & 0.0139 & -0.1309 & 0.1515 & -0.1110 & 0.1533 \\
\hline 300 & -0.1071 & 0.1105 & 0.0137 & -0.1256 & 0.1026 & -0.1073 & 0.1060 \\
\hline 320 & -0.0864 & 0.0654 & 0.0139 & -0.1029 & 0.0578 & -0.0844 & 0.0618 \\
\hline 340 & -0.0484 & 0.0295 & 0.0139 & -0.0633 & 0.0236 & -0.0468 & 0.0267 \\
\hline 360 & -0.0002 & 0.0080 & 0.0136 & -0.0145 & 0.0037 & 0.0020 & 0.0061 \\
\hline
\end{tabular}

some proportion mismatches between each axis. We found the servo mismatches to be $0.02 \mathrm{~ms}, 0.12 \mathrm{~ms}$, and $0.18 \mathrm{~ms}$ between each axis during the processes

Table 2. The change values $\Delta l$ of DBB bar length when measuring $B$ swinging head

\begin{tabular}{|c|c|c|c|c|c|c|}
\hline \multirow{2}{*}{$\begin{array}{c}\text { Angles } \\
\left.{ }^{0}\right]\end{array}$} & \multicolumn{3}{|c|}{$\Delta l_{1}[\mathrm{~mm}]$} & \multicolumn{3}{|c|}{$\Delta l_{2}[\mathrm{~mm}]$} \\
\hline & Radial & Tang. & Axial & Radial & Tang. & Axial \\
\hline 0 & -0.0023 & 0.0145 & -0.0095 & 0.0013 & 0.0019 & 0.0082 \\
\hline-5 & -0.0030 & 0.0123 & -0.0098 & -0.0010 & -0.0009 & 0.0083 \\
\hline-10 & -0.0029 & 0.0111 & -0.0093 & -0.0024 & -0.0025 & 0.0089 \\
\hline-15 & -0.0028 & 0.0089 & -0.0085 & -0.0037 & -0.0056 & 0.0095 \\
\hline-20 & -0.0027 & 0.0075 & -0.0081 & -0.0047 & -0.0079 & 0.0101 \\
\hline-25 & -0.0022 & 0.0054 & -0.0076 & -0.0053 & -0.0107 & 0.0103 \\
\hline-30 & -0.0015 & 0.0045 & -0.0075 & -0.0063 & -0.0123 & 0.0104 \\
\hline-35 & -0.0003 & 0.0037 & -0.0065 & -0.0068 & -0.0142 & 0.0114 \\
\hline-40 & 09 & 0.0037 & -0.0064 & -0 . & -0.0162 & 0. \\
\hline-45 & 0.0020 & 0.0031 & -0.0062 & -0.0065 & -0.0188 & 0.0122 \\
\hline-50 & 0.0043 & 0.0020 & -0.0057 & -0.0057 & -0.0198 & 0.0126 \\
\hline-55 & & 0.0023 & -0.0 & -0 & -0.0206 & 0 \\
\hline-60 & 0.0080 & 0.0026 & -0.0040 & -0.0031 & -0.0219 & 0.0149 \\
\hline-65 & 0.0094 & 0.0032 & -0.0037 & -0.0023 & -0.0229 & 0.0152 \\
\hline-70 & 0.0117 & 0.0042 & -0.0036 & -0.0009 & -0.0233 & 0.0154 \\
\hline-75 & 0.0139 & 0.0055 & -0.0039 & 0.0012 & -0.0239 & 0.0153 \\
\hline-80 & 0.0148 & 0.0064 & -0.0044 & 0.0023 & -0.0242 & 0.0146 \\
\hline-85 & 0.0166 & 0.0081 & -0.0040 & 0.0034 & -0.0246 & 0.0149 \\
\hline-90 & 0.0185 & 0.0102 & -0.0039 & 0.0056 & -0.0237 & 0.0151 \\
\hline-95 & 0.0203 & 0.0139 & -0.0034 & 0.0078 & -0.0211 & 0.0155 \\
\hline-100 & 0.0212 & 0.0183 & -0.0025 & 0.0093 & -0.0173 & 0.0168 \\
\hline
\end{tabular}

of measurement. Hence, the reason leading to the proportion mismatches is probably the adjustment deviation of servo parameters. Even so, the results can still demonstrate the good accuracy of the machine tool.

It can be seen from the above analyses that the process to obtain the geometric errors of the translational axes is direct. However, the attitude errors of the rotational axes are more difficult to measure. Therefore, the identification model is necessary.

The data collected in the process of the experiment included the actual bar length of the DBB. After finishing the data collection for each measurement mode, we obtained the changes in DBB bar length and calculated their averages shown in Tables 1 and 2 .

\subsection{Analysis of Experimental Results}

$\delta_{z i}(C)=\Delta l_{a 1 i}$ can be directly measured by the error identification model for the $C$ turntable. Six equations in the model include five errors in the $C$ turntable: the least-squares solution to the system of overdetermined equations is obtained by MATLAB ${ }^{\mathrm{TM}}$, and each error is obtained as shown in Figs. 18 and 19.

Based on the errors obtained from the identification model, the maximum, minimum and average values of each axis for the $C$ turntable are shown in Table 3. 


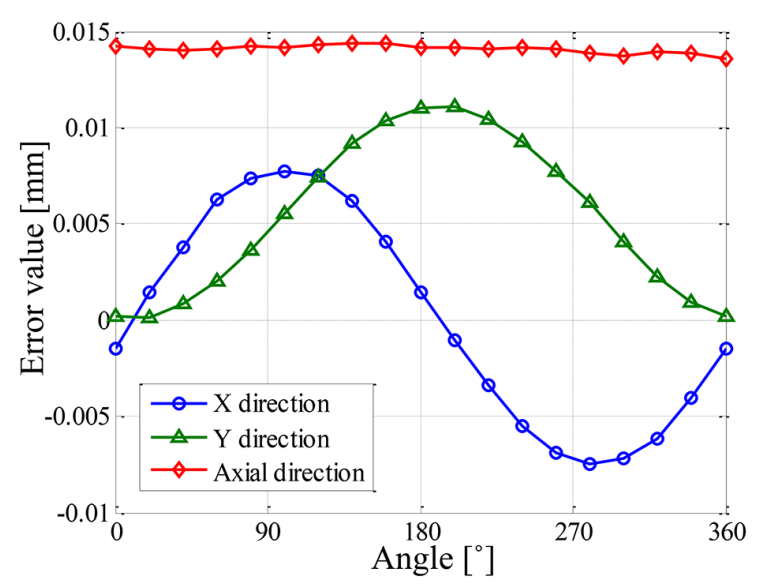

Fig. 18. Displacement error: C turntable

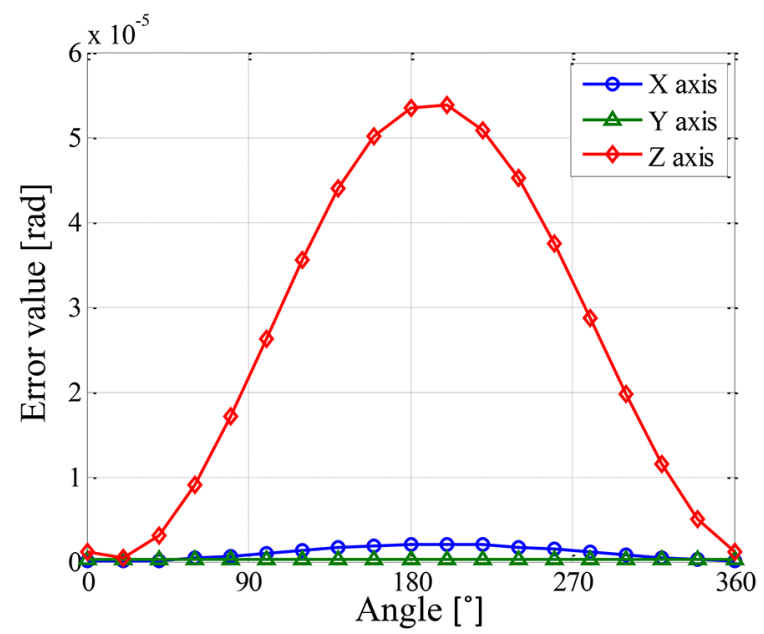

Fig. 19. Angular error: C turntable

Table 3. The maximum, minimum, and average values of each axis for the $\mathrm{C}$ turntable

\begin{tabular}{|c|c|c|c|c|c|c|}
\hline & \multicolumn{3}{|c|}{$\begin{array}{c}\text { Displacement errors } \\
{\left[10^{-3} \mathrm{~mm}\right]}\end{array}$} & \multicolumn{3}{|c|}{$\begin{array}{c}\text { Angular errors } \\
{\left[10^{-5} \mathrm{rad}\right]}\end{array}$} \\
\hline & $X$ & $Y$ & Axial & $X$ & $Y$ & $Z$ \\
\hline Max & 7.71 & 11.1 & 14.4 & 0.205 & 0.031 & 5.37 \\
\hline Min & -7.5 & 0.018 & 13.6 & 0.002 & 0.02 & 0.047 \\
\hline Avg & 0.061 & 5.386 & 14.079 & 0.1 & 0.026 & 2.595 \\
\hline
\end{tabular}

Then, using the identification model for the $\mathrm{B}$ swinging head, and the measured data, six errors in the B swinging head at each angle are obtained using

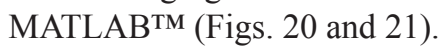

Based on the errors obtained from the identification model, the maximum, minimum and average values of each axis for the $B$ swinging head are shown in Table 4.

The experimental results indicate that the displacement errors of both the $C$ turntable and $B$ swinging head are the greatest in their axial directions, at $14.4 \mu \mathrm{m}$ and $22 \mu \mathrm{m}$, respectively; however, the displacement errors are smaller in the other directions. In terms of the angular errors, the largest angular errors around the $X, Y$, and $Z$ axes of the $C$ turntable and the $B$ swinging head are $5.46 \times 10^{-5} \mathrm{rad}, 2.56 \times 10^{-5}$ $\mathrm{rad}$, and $5.37 \times 10^{-5} \mathrm{rad}$.

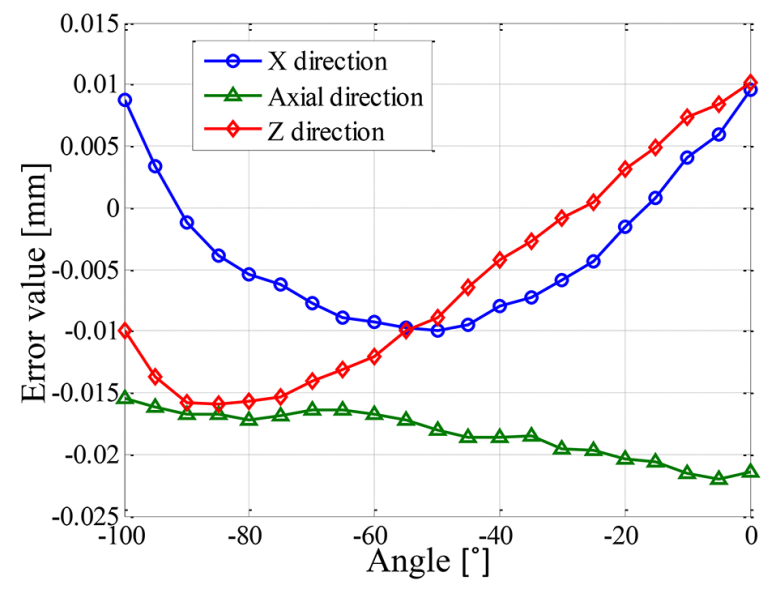

Fig. 20. Displacement error: B swinging head

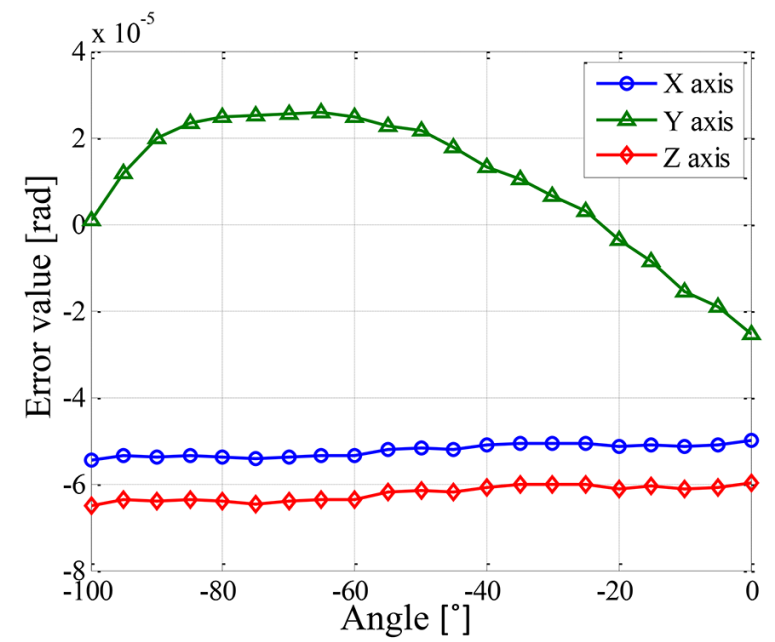

Fig. 21. Angular error: $B$ swinging head

Table 4. The maximum, minimum, and average values of each axis for the B turntable

\begin{tabular}{|c|c|c|c|c|c|c|}
\hline & \multicolumn{3}{|c|}{$\begin{array}{c}\text { Displacement errors } \\
{\left[10^{-3} \mathrm{~mm}\right]}\end{array}$} & \multicolumn{3}{|c|}{$\begin{array}{c}\text { Angular errors } \\
{[10-5 \mathrm{rad}]}\end{array}$} \\
\hline & $X$ & Axial & $Z$ & $X$ & $Y$ & $Z$ \\
\hline Max & 9.54 & -15.5 & 10.1 & -5.01 & 2.56 & -5.97 \\
\hline Min & -9.98 & -22 & $\begin{array}{l}-16 \\
\end{array}$ & -5.46 & -2.55 & -6.51 \\
\hline Avg & -3.16 & -18.32 & -5.94 & -5.23 & 0.97 & -6.23 \\
\hline
\end{tabular}

Compared with the translational axes, the attitude errors of the rotational axes are harder to measure 
directly. Therefore, the proposed method can be used to measure and identify geometric errors for rotational axes.

\section{CONCLUSIONS}

The geometric errors of five-axis CNC machine tools usually need to be measured in production. The method of the DBB is simple, convenient, and efficient, so it is commonly used. However, this instrument cannot provide the measurement of the attitude errors for machine tools. In this paper, the $\mathrm{B} / \mathrm{C}$ type of five-axis $\mathrm{CNC}$ machine tool was examined. A method of identifying the attitude errors of the machine tool was studied based on the DBB, which was used to measure the errors of the machine tool in production sites efficiently. Different installation and combination methods of the DBB were designed in three directions. Seven measurements were implemented under three measurement modes. Then, the attitude errors of the machine tool were obtained by the identification models.

The straightness, squareness, and backlash errors of the machine tool could be obtained directly by the DBB measurement system. According to the measurement results, the straightness errors of each axis are not greater than $2.5 \mu \mathrm{m}$. The squareness errors between any two axes are less than $13 \mu \mathrm{m} / \mathrm{m}$. The backlash errors of each axis are less than $0.5 \mu \mathrm{m}$. Additionally, the roundness errors are $6.1 \mu \mathrm{m}, 8.6$ $\mu \mathrm{m}$, and $7.4 \mu \mathrm{m}$ on three planes. The main geometric accuracies of the machine tool are within the range of the accuracy requirements.

The angular errors were identified by the method of the DBB. The largest angular errors around the $X$, $Y$, and $Z$ axes of the $C$ turntable and the $B$ swinging head are $5.46 \times 10^{-5} \mathrm{rad}, 2.56 \times 10^{-5} \mathrm{rad}$, and $5.37 \times 10^{-5}$ rad. Based on the measured and identified results, it indicates that the method adopted in this paper is effective. Therefore, it can be used as a reference to evaluate the errors of the machine tool in future production.

\section{ACKNOWLEDGEMENTS}

This work is supported by the National Science and Technology Major Project of China under grant 2014ZX04014-031.

\section{REFERENCES}

[1] Klobucar, R., Acko, B. (2017). Automatic high resolution measurement set-up for calibrating precise line scales.
Advances in Production Engineering \& Management, vol. 12, no. 1, p. 88-96, Dol:10.14743/apem2017.1.242.

[2] Hrelja, M., Klancnik, S., Irgolic, T., Paulic, M., Jurkovic, Z., Balic, J., Brezocnik, M. (2014). Particle swarm optimization approach for modelling a turning process. Advances in Production Engineering \& Management, vol. 9, no. 1, p. 2130, DOI:10.14743/apem2014.1.173.

[3] Hrelja, M., Klancnik, S., Balic, J., Brezocnik, M. (2014). Modelling of a turning process using the gravitational search algorithm. International Journal of Simulation Modelling, vol. 13, no. 1, p. 30-41, D0I:10.2507/IJSIMM13(1)3.248.

[4] Schwenke, H., Knapp, W., Haitjema, H., Weckenmann, A., Schmitt, R., Delbressine, F. (2008). Geometric error measurement and compensation of machines-An update. CIRP Annals-Manufacturing Technology, vol. 57, no. 2, p. 660675, D0l:10.1016/j.cirp.2008.09.008.

[5] Vignat, F., Nguyen, D.S., Brissaud, D.A. (2012). Method to determine the impact of geometrical deviations on product performance. Strojniški vestnik - Journal of Mechanical Engineering, vol. 58, no. 9, p. 517-526, Dol:10.5545/svjme.2011.268.

[6] Xiang, S., Yang, J. (2014). Using a double ball bar to measure 10 position-dependent geometric errors for rotary axes on five-axis machine tools. The International Journal of Advanced Manufacturing Technology, vol. 75, no. 1-4, p. 559-572, DOI:10.1007/s00170-014-6155-2.

[7] Bryan, J.B. (1982). A simple method for testing measuring machines and machine tools Part 1: principles and application. Precision Engineering, vol. 4, no. 2, p. 61-69, DOI:10.1016/0141-6359(82)90018-6.

[8] Tsutsumi, M., Saito, A. (2003). Identification and compensation of systematic deviations particular to 5-axis machining centers. International Journal of Machine Tools and Manufacture, vol. 43, no. 8, p. 771-780, Dol:10.1016/S08906955(03)00053-1.

[9] Tsutsumi, M., Saito, A. (2004). Identification of angular and positional deviations inherent to 5-axis machining centers with a tilting-rotary table by simultaneous fouraxis control movements. International Journal of Machine Tools and Manufacture, vol. 44, no. 12-13, p. 1333-1342, D0I:10.1016/j.jjmachtools.2004.04.013.

[10] Chen, J.X., Lin, S.W., He, B.W. (2014). Geometric error measurement and identification for rotary table of multiaxis machine tool using double ballbar. International Journal of Machine Tools \& Manufacture, vol. 77, p. 47-55, D0l:10.1016/j.ijmachtools.2013.10.004.

[11] Ji, S., Yu, H., Zhao, J., Liu, X., Zhao, M. (2016). Ultra-precision machining of a large amplitude sinusoidal ring surface based on slow tool servo. Strojniški vestnik - Journal of Mechanical Engineering, vol. 62, no. 4, p. 213-219, Dol:10.5545/svjme.2015.2528.

[12] Jiang, X., Cripps, R.J. (2015). A method of testing position independent geometric errors in rotary axes of a five-axis machine tool using a double ball bar. International Journal of Machine Tools and Manufacture, vol. 89, p. 151-158, DOI:10.1016/j.ijmachtools.2014.10.010.

[13] Chen, G.S., Mei, X.S., Li, H.L. (2013). Geometric error modeling and compensation for large-scale grinding machine tools with 
multi-axes. International Journal of Advanced Manufacturing Technology, vol. 69, no. 9-12, p. 2583-2592, D0l:10.1007/ s00170-013-5203-7.

[14] Zhang, Y., Yang, J.G., Zhang, K. (2013). Geometric error measurement and compensation for the rotary table of fiveaxis machine tool with double ballbar. International Journal of Advanced Manufacturing Technology, vol. 65, no. 1-4, p. 275281, D0I:10.1007/s00170-012-4166-4.

[15] Zhu, S.W., Ding, G.F., Qin, S.F, Lei, J., Zhuang, L., Yan, K.Y. (2012). Integrated geometric error modeling, identification and compensation of CNC machine tools. International Journal of Machine Tools and Manufacture, vol. 52, no. 1, p. 24-29, D0I:10.1016/j.jijmachtools.2011.08.011.

[16] Sharif Uddin, M., Ibaraki, S., Matsubara, A., Matsushita, T. (2009). Prediction and compensation of machining geometric errors of five-axis machining centers with kinematic errors. Precision Engineering, vol. 33, no. 2, p. 194-201, D0l:10.1016/j.precisioneng.2008.06.001.

[17] Lasemi, A., Xue, D., Gu, P. (2016). Accurate identification and compensation of geometric errors of 5-axis CNC machine tools using double ball bar. Measurement Science and Technology, vol. 27, no. 5, p. 55004-55021, DOI:10.1088/0957. 0233/27/5/055004.

[18] Ni, Y.B., Zhang, B., Guo, W.X., Shao, C.Y. (2016). Kinematic calibration of parallel manipulator with full-circle rotation. Industrial Robot, vol. 43, no. 3, p. 296-307, D0l:10.1108/IR08-2015-0161.

[19] Ni, Y.B., Zhang, B., Sun, Y.P., Zhang, Y. (2016). Accuracy analysis and design of $A 3$ parallel spindle head. Chinese Journal of Mechanical Engineering, vol. 29, no. 2, p. 239-249, DOI:10.3901/CJME.2015.1210.144.
[20] Lei, W.T., Hsu, Y.Y. (2003). Error measurement of five-axis CNC machines with 3D probe-ball. Journal of Materials Processing Technology, vol. 139, no. 1-3, p. 127-133, Dol:10.1016/ S0924-0136(03)00193-6.

[21] Weikert, S. (2004). R-test, a new device for accuracy measurements on five axis machine tools. CIRP Annals - Manufacturing Technology, vol. 53, no. 1, p. 429-432, D0I:10.1016/S0007-8506(07)60732-X.

[22] Zargarbashi, S.H.H., Mayer, J.R.R. (2009). Single setup estimation of a five-axis machine tool eight link errors by programmed end point constraint and on the fly measurement with Capball sensor. International Journal of Machine Tools \& Manufacture, vol. 49, no. 10, p. 759-766, D0l:10.1016/j. ijmachtools.2009.05.001.

[23] Kosler, H., Pavlovčič, U., Jezeršek, M., Možina, J. (2016). Adaptive robotic deburring of die-cast parts with position and orientation measurements using a 3D laser-triangulation sensor. Strojniški vestnik - Journal of Mechanical Engineering, vol. 62, no. 4, p. 207-212, D0l:10.5545/sv-jme.2015.3227.

[24] Rejc, J., Munih, M. (2016). Robust visual touch-up calibration method in robot laser spot welding application. Strojniški vestnik - Journal of Mechanical Engineering, vol. 62, no. 12, p. 697-708, DOI:10.5545/sv-jme.2016.3708.

[25] Wang, J., Guo, J., Zhang, G., Guo, B., Wang, H. (2012). The technical method of geometric error measurement for multiaxis NC machine tool by laser tracker. Measurement Science and Technology, vol. 23, no. 4, p. 1-11, D0l:10.1088/09570233/23/4/045003.

[26] Wang, J.D., Guo, J.J., Zhou, B.Q., Xiao, J. (2012). The detection of rotary axis of NC machine tool based on multi-station and time-sharing measurement. Measurement, vol. 45, no. 7, p. 1713-1722, D0I:10.1016/j.measurement.2012.04.015. 